\title{
Endobronchial carcinoid tumor: Radiological findings of a clinical case
}

\author{
Rodolfo Mendes Queiroz ${ }^{1 *}$ (D), Danilo Brotto Ferreira de Santana ${ }^{1}$, Rogério Nastri Filho ${ }^{1}$, Gláucia Aparecida Magnani \\ Landell $^{2}$, Paulo Roberto Félix ${ }^{2}$, Marcus Vinícius Nascimento Valentin ${ }^{1}$
}

1Department of Radiology and Medical Imaging, Documenta - Hospital São Francisco, Ribeirão Preto, SP, Brazil

${ }^{2}$ Department of Anatomical Pathology, Cytopathology and Histology; Anatomical Pathology and Cytopathology Unit, Prof. Dr. Humberto de Queiroz Menezes, Ribeirão Preto, SP, Brazil

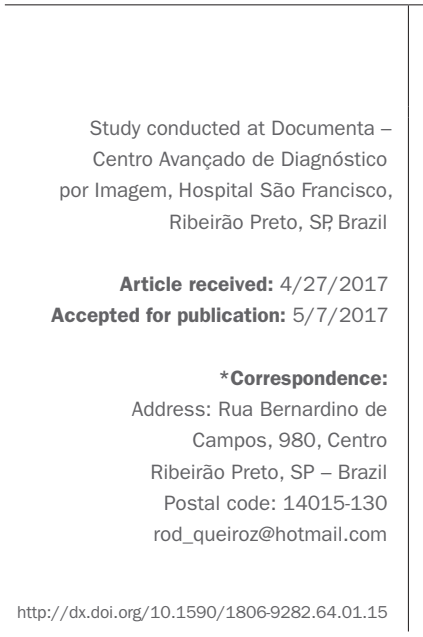

\section{Case report}

A female 21-year old patient presenting dyspnea and wheezing attacks for two years. She is overweight, has polycystic ovary syndrome and is currently using oral contraceptives. She does not smoke. The patient reported that three radiographs in the past 6 months revealed consolidation in the left lung base. During this period, treatment regimens for pneumonia were used, without clinical or radiological improvement. On auscultation, rhonchi and wheezing were audible at the base of the left hemithorax. Laboratory tests did not point out any abnormalities.

A new chest X-ray showed loss of volume in the left lower lobe with triangular basal retrocardiac opacity, apex directed towards the ipsilateral hilum and base next to the diaphragmatic dome (Figures 1A and 1B).

Computed tomography (CT) imaging showed a solid expansive mass with apex protruding into the left source bronchus ("tip of the iceberg" sign ${ }^{1}$ ), causing partial obstruction and distal subsegmentar atelectasis, as well as marked enhancement following intravenous contrast administration (Figures 2A, 2B, 2C and 2D).

After bronchofibroscopy, which confirmed the endobronchial lesion, the anatomopathological and immunohistochemical investigation of the transbronchial biopsy material showed a well-differentiated (typical) carcinoid tumor (Figures 3A, 3B and 3C). A CT scan of the abdomen performed for staging failed to show other neoplastic formations. The therapy selected was left total pneumonectomy, which confirmed the histological finding of tumor in a subsequent investigation.

\section{Discussion}

Carcinoid tumors (CATUs) are neuroendocrine neoplasms originating from enterochromaffin cells, commonly found in the gastrointestinal tract. Occurrence in the respiratory tract corresponds to $10-30 \%$ of all cases,${ }^{1-6}$ with a bronchopulmonary incidence of 0.22 to $1.57 / 100,000 .^{2-4}$

They represent up to $2 \%$ of lung malignancies, ${ }^{1,2}$ often presenting indolent behavior. ${ }^{1-3,5}$ Histologically, these tumors are classified as typical (76-90\%) or atypical. ${ }^{1-4}$ Central bronchial CATUs represent $64-85 \%$ of the cases, with a predominance of typical tumors. ${ }^{1-3}$

Typical CATUs affect both sexes, ${ }^{1-3}$ with some studies reporting a higher prevalence in women. ${ }^{2,3}$ They have two peaks of incidence: one in adolescence and another near the age of 45 years. ${ }^{1}$ Metastases occur in $15 \%{ }^{1}$

Symptoms are more frequent in tumors at central sites and some of the main manifestations include recurrent pneumonia, chest pain, cough, hemoptysis and localized wheezing. ${ }^{1-3,6,7}$ These tumors can secrete neuroamines and peptide hormones, especially serotonin, growth hormone and adrenocorticotrophic hormone, and may cause carci- 


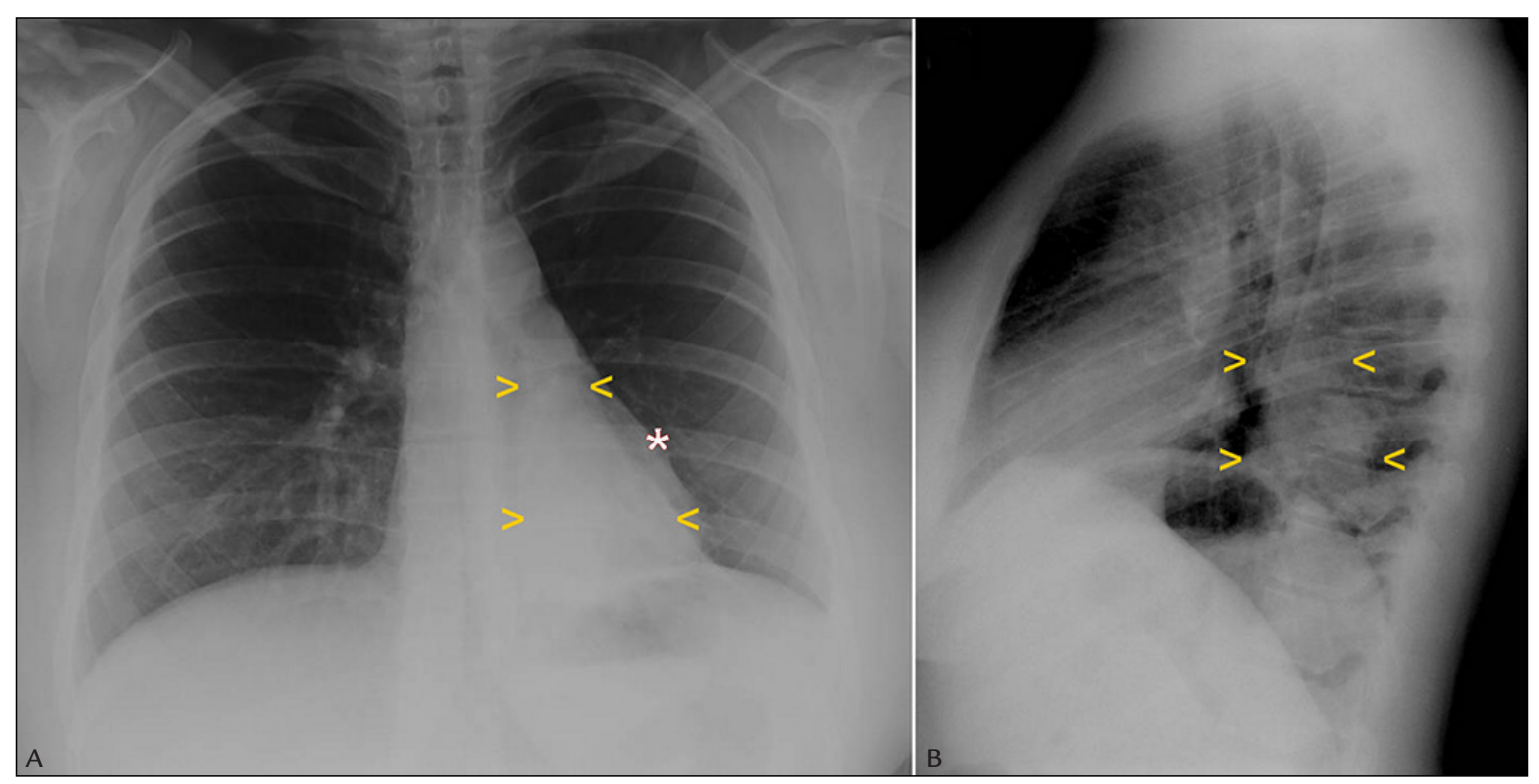

FIGURE 1 Chest radiographs in posteroanterior (A) and lateral (B) view revealing opacity at the left lung base (yellow arrowheads) within the retrocardiac space, appearing predominantly triangular with apex converging to the pulmonary hilum and base blurring of the edges of the diaphragm dome. Note the difference between the edges of the opacity in relation to the cardiac silhouette $(*)$.

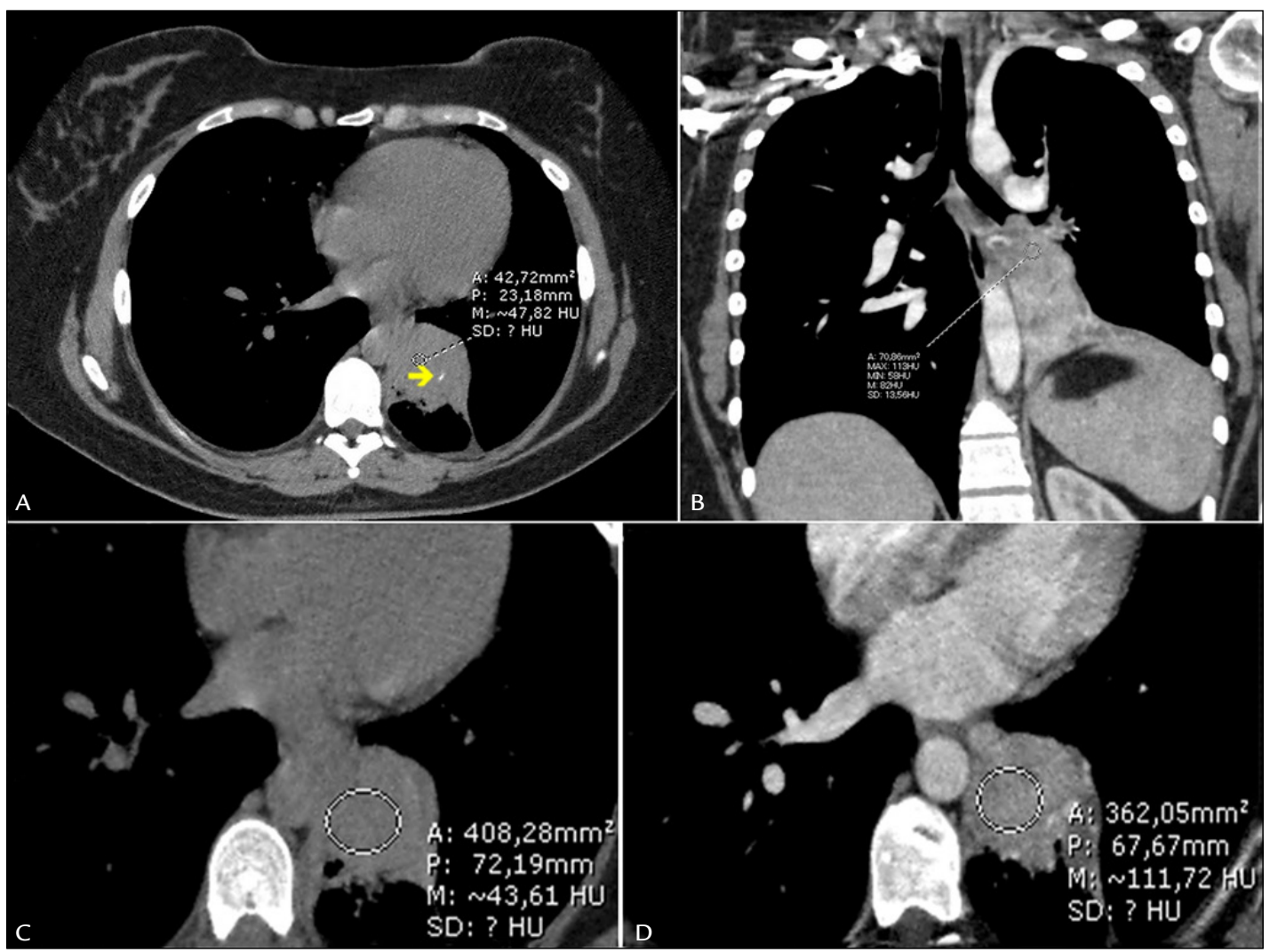

FIGURE 2 Computed tomography scan of the thorax, mediastinal window, without contrast medium (A, C) and after administration of intravenous iodate contrast agent (B, D), revealing a left infrahilar lung mass causing subsegmentar atelectasis of the ipsilateral inferior lobe, with exophytic nodular component protruding into the lumen of the left main and lower subsegmental bronchi. We found scarce punctiform calcifications and diffuse linear foci (A, yellow arrow), as well as accentuated enhancement with contrast medium (B, D) in the extensive mass. 


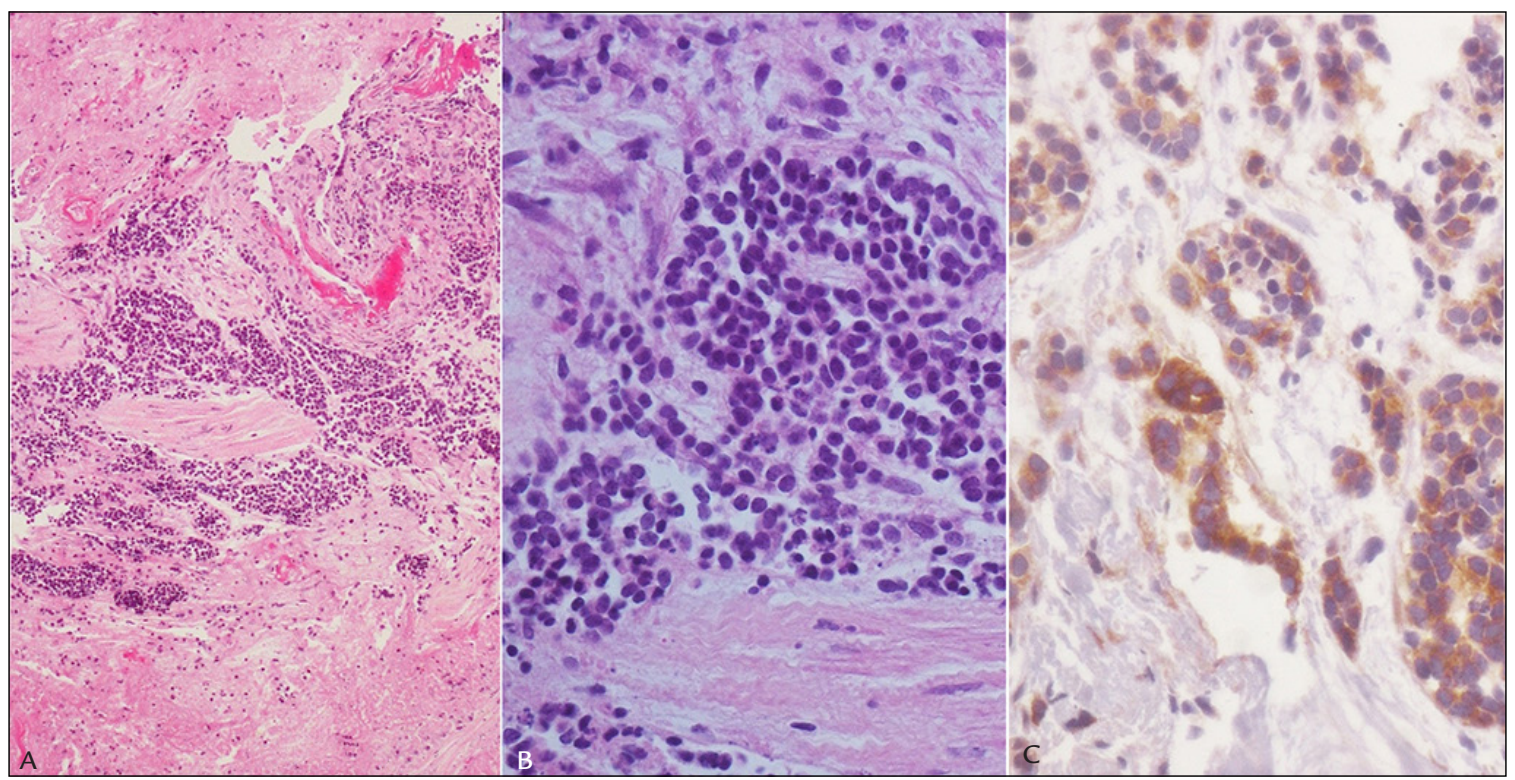

FIGURE 3 A and B. HE staining, showing differentiated small cell epithelial proliferation with rounded, non-pleomorphic nuclei and granular chromatin, with a "salt and pepper" appearance of the tissue. C. Immunohistochemistry with chromogranin A showing cytoplasmic expression of gold-brown DAB in neoplastic cells.

noid syndrome, acromegaly and Cushing's disease (2\%), especially in the presence of metastases, with an emphasis on the liver as site of secondary implantation. ${ }^{1,3}$

Radiographs generally reveal well-defined hilar/perihilar masses, rounded or ovoid in shape, associated or not with distal parenchymal disease, such as consolidations or atelectasis. It is rarely possible to distinguish an endoluminal component, with extension to the parenchyma being the most dominant feature. .-3,-9 $^{-3}$

On CT scan, the presence of two central sites is common ( $85 \%$ in the main, lobar or segmental bronchi), with an appearance of nodule or ovoid mass, well-defined and regular margins, spontaneously hyperdense, associated or not with a distinct endoluminal component or distal parenchymal complications. Punctual or diffuse calcifications are found in $30 \%$ of the cases. The stroma in these tumors is typically well-vascularized with homogeneous and intense contrast enhancement. ${ }^{1-3,7-9}$

Despite the primarily endoluminal origin, it is typically observed on CT that most of the mass extends to the adjacent parenchyma, and the endoluminal component may be minimal. This finding is what is called the "tip of the iceberg" sign. ${ }^{1,8,9}$

Prognosis is most often favorable and varies with the typical or atypical character of the lesion, tumor resectability, lymphatic or metastatic dissemination. For staging purposes, the TNM protocol is used for lung neoplasms, and stage I, II and IIIA tumors are considered resectable. ${ }^{1-3,7-9}$
In cases of localized neoplasia, both in the typical and atypical forms, the treatment of choice is tumor resection, with a tendency to preserve as much healthy lung tissue as possible. ${ }^{2,10,11}$ Survival rates for the typical and atypical forms 5 and 10 years after surgery are $90 \%$ and $80 \%$, and $70 \%$ and $50 \%$, respectively. ${ }^{10}$ In advanced disease, however, this therapeutic alternative is contraindicated, as there is no evidence that extended surgery can improve the prognosis, ${ }^{11}$ which leaves the option of using somatostatin analogs for disease stabilization. ${ }^{10}$ In the case of hepatic and lymph node metastases, surgical removal of tumors is primarily intended to relieve symptoms. ${ }^{1,10}$ The use of adjuvant chemotherapy and radiotherapy is controversial in the literature ${ }^{10,11}$ and there is no consensus. Nevertheless, there are reports of patients with atypical carcinoid tumors who would benefit from these treatments. ${ }^{11}$

\section{Resumo}

Tumor carcinoide endobrônquico: aspectos radiológicos em um caso clínico

Descrevemos um caso de paciente do gênero feminino, 21 anos, apresentando crises de dispneia e sibilância há 2 anos. Radiografia torácica evidenciou perda volumétrica do lobo inferior esquerdo e opacidade triangular basal retrocardíaca ipsilateral. Tomografia computadorizada mostrou 
formação expansiva sólida com ápice protruindo para o interior dos brônquios principal e lobar inferior esquerdos, promovendo atelectasia distal. Estudos anatomopatológico e imuno-histoquímico após biópsia transbrônquica da lesão diagnosticaram um tumor carcinoide típico, confirmado após ressecção tumoral com pneumectomia total esquerda.

Palavras-chave: Tumor Carcinoide. Endobrônquico. Pulmonar. Típico. Diagnóstico por Imagem.

\section{References}

1. Jeung MY, Gasser B, Gangi A, Charneau D, Ducroq X, Kessler R, et al Bronchial carcinoid tumors of the thorax: spectrum of radiologic findings. Radiographics. 2002; 22(2):351-65.

2. Naalsund A, Rostad H, Strøm EH, Lund MB, Strand TE. Carcinoid lung tumors: incidence, treatment and outcomes: a population-based study. Eur J Cardiothorac Surg. 2011; 39(4):565-9.
3. Meisinger QC, Klein JS, Butnor KJ, Gentchos G, Leavitt BJ. CT features of peripheral pulmonary carcinoid tumors. AJR Am J Roentgenol. 2011; 197(5):1073-80.

4. Lopes AF, Cavicchioli M, Lima ENP, Chojniak R. Utilização do 111-in octreotide na avaliação de patologia secundária a tumor carcinoide. Rev Assoc Med Bras. 2006; 52(5):292.

5. Santos MK, Barreto ARF, Chagas Neto FA, Muglia VF, Elias Jr J. Neuroendocrine tumors of the lung: major radiologic findings in a series of 22 histopathologically confirmed cases. Radiol Bras. 2012; 45(4):191-7.

6. Westphal FL, Lima LC, Lima Netto JC, Cardoso MS, Silva MS, Westphal DC. Carcinoid tumor and pulmonary sequestration. J Bras Pneumol. 2012;38(1):133-7.

7. Dusmet ME, McKneally MF. Pulmonary and thymic carcinoid tumors. World J Surg. 1996; 20(2):189-95.

8. Naidich DP. CT/MR correlation in the evaluation of tracheobronchial neoplasia. Radiol Clin North Am. 1990; 28(3):555-71.

9. Aronchick JM, Wexler JA, Christen B, Miller W, Epstein D, Gefter WB. Computed tomography of bronchial carcinoid. J Comput Assist Tomogr. 1986; 10(1):71-4

10. Wolin EM. Challenges in the diagnosis and management of well-differentiated neuroendocrine tumors of the lung (typical and atypical carcinoid): current status and future considerations. Oncologist. 2015; 20(10):1123-31.

11. Herde RF, Kokeny KE, Reddy CB, Akerley WL, Hu N, Boltax JP, et al. Primary pulmonary carcinoid tumor: a long-term single institution experience. Am J Clin Oncol. 2018; 41(1):24-9. 